\title{
Sociodemographic, ethnic and dietary factors associated with childhood obesity in Thessaloniki, Northern Greece
}

\author{
Maria Hassapidou' ${ }^{1}$, Sousana K. Papadopoulou ${ }^{1}$, Athanasios Frossinis ${ }^{2}$, \\ Ioannis Kaklamanos ${ }^{2}$, Themistoklis Tzotzas ${ }^{2}$ \\ ${ }^{1}$ Department of Nutrition and Dietetics Technological Educational Institution of Thessaloniki, ${ }^{2}$ Hellenic Medical \\ Association for Obesity, Greece
}

\begin{abstract}
OBJECTIVE: To investigate sociodemographic, ethnic and dietary factors associated with the development of childhood obesity. DESIGN: 276 children, aged 8-12 years, randomly selected from seven schools in Thessaloniki, Northern Greece, participated in the study. $13 \%$ of the children were immigrants from neighboring Balkan countries and ex-Soviet Union countries. Data was collected using specific validated questionnaires. Anthropometric measurements, dietary intake and physical activity assessment were carried out for all children. RESULTS: 26.1\% of the boys and $22.4 \%$ of the girls were overweight and a further $11.6 \%$ of boys and $10.9 \%$ of girls were obese. The overweight and obesity rate was significantly lower in immigrants $(10 \%$ and 3.3\%) compared to Greeks $(25.8 \%$ and $12.7 \%), p=0.024$. Obese children compared to their non-obese counterparts a) had parents who were obese at a higher percentage $(p=0.001)$, b) reported that food preparation was carried out by their grandmother $(p=0.006)$ and $c)$ had less pocket money $(p=0.004)$. Daily energy and carbohydrate intakes were significantly higher in immigrants compared to Greeks $(1611 \pm 599 \mathrm{Kcal}$ vs $1363 \pm 471 \mathrm{Kcal}, p=0.036$ and $188.31 \pm 70.63 \mathrm{~g}$ vs $149.87 \pm 56.41 \mathrm{~g}, \mathrm{p}=0.001)$ and the same was true for exercise $(6.38 \pm 7.22 \mathrm{~h} / \mathrm{w}$ vs $4.14 \pm 4.18 \mathrm{~h} / \mathrm{w}$, $\mathrm{p}=0.049$ ). CONCLUSIONS: In planning interventions for childhood obesity, sociodemographic factors in addition to food intake and physical activity patterns have to be considered.
\end{abstract}

Key words: Children, Dietary, Immigrants, Northern Greece, Obesity, Physical activity, Sociodemographic factors, Thessaloniki

\section{INTRODUCTION}

Obesity in childhood constitutes a rising epidemic in many parts of the world, including in particular

\section{Address for correspondence:}

Prof. Maria N. Hassapidou, Dept. of Nutrition and Dietetics, Technological Educational Institution of Thessaloniki, P.O. Box 14561, 54101 Thessaloniki, Greece, Tel: +302310791386, Fax: +302310791386, e-mail: mnhas@nutr.teithe.gr Received 05-05-08, Revised 10-09-08, Accepted 10-10-08 the USA, ${ }^{1}$ Australia ${ }^{2}$ and Europe. ${ }^{3,4}$ An imbalance between energy intake and energy expenditure can lead to weight gain and in the long run to overweight and obesity. During the last few decades, there have been changes in food habits, such as an increase in the consumption of foods high in fat and protein, low intake of fiber and increased intake of sugar and sweetened drinks, all of which have obviously contributed to the high obesity rates. ${ }^{5,6}$ However, other 
factors such as decrease in physical activity through an increasingly motorized lifestyle, fewer recreational areas and longer usage of media constitute other key factors contributing to the rising prevalence of overweight and obesity. Other influential factors are changes in the living conditions of children and their families, urbanization and migration. ${ }^{6}$

Dietary and sedentary behaviours leading to obesity are established during childhood. Therefore, the overconsumption of candies, soft drinks, pre-prepared and fast foods, the increased time spent in television watching, the Internet and video games and the decreased time spent in strenuous activities are factors leading to obesity. 7,8

Behavioral changes in culture and diet are principally associated with migration to another country. For some immigrants, the abandonment of a balanced traditional diet and the westernization of dietary habits can lead to obesity and related diseases like diabetes, hypertension and cardiovascular diseases. ${ }^{9}$ In Greece, although migration from Eastern European countries has occured during the last decade, to the best of our knowledge, no study has been carried out up to now to investigate the dietary habits of immigrant children in Greece.

Effective intervention in childhood obesity necessitates a better understanding of the factors related to its prevalence. For the prevention of pediatric obesity, it is essential to identify the modifiable risk factors, including diet and exercise. ${ }^{10}$ The aim of this study was to investigate the role of sociodemographic, ethnic and dietary factors in the development of childhood obesity in a sample of primary public schools in the city of Thessaloniki in Northern Greece.

\section{MATERIALS AND METHODS}

Overall, 276 children, aged 8-12yr, equally distributed in both sexes (boys: 138 and girls: 138) participated in this study, which was conducted from March 2006 to October 2006. The sample was chosen via the method of stratified sampling from seven schools, four representative of the city and three representative of the suburbs. Thirty-six children (13\%) were immigrants from neighboring Balkan countries and ex-Soviet Union countries. Valid anthropometric measurements were taken from 266 children (130 boys and 136 girls), of whom 236 were Greeks and 30 were immigrants.

Anthropometric measurements [weight, height, waist and hip circumference and 5 skinfolds (subscapular, triceps, thigh, abdomen, suprailiac)] were carried out by the same experienced dietician in order to avoid inter-examiner variability. Body weight was measured with a digital scale with an accuracy of $\pm 100 \mathrm{~g}$ (Seca 707, Seca Corporation, Columbia, USA), while height was measured to the nearest $0.5 \mathrm{~cm}$ with the use of stadiometer, with an accuracy of $0.5 \mathrm{~cm}$ (SECA 220). Skinfold thicknesses were measured using a Harpenden skinfold caliper (British Indicator, Ltd, London) in duplicate and the average measurement was used. In the event that there was a discrepancy of above $10 \%$ between duplicate measurements, the measurement was repeated.

Percentage (\%) of body fat was estimated according to Slaughter et al. equations. ${ }^{11}$ Body weight status was categorized according to BMI values, based on the IOTF recommended cut-off criteria. ${ }^{12}$

We also assessed parental obesity by asking parents of the children to report their body weight and height values on their children's questionnaire.

Dietary intakes were assessed using 24-hour recalls and a weekly food frequency questionnaire. All socioeconomic and dietary data were collected with the help of the parents by using specific validated questionnaires. The following factors were examined and analysed: country of origin, total energy intake ( $\mathrm{Kcal} / \mathrm{d})$ and macronutrient intake $(\mathrm{g} / \mathrm{d})$, exercise (hours/w), time spent on television viewing and computer occupation (hours/w), pocket money (euros/d), food preparer in the family, educational level and income of the parents. ${ }^{13,14}$ Ethical approval was given by the Greek Ministry of Education. Validated responses were collected for a total of 276 children (138 boys and 138 girls). We used the Kolmogorov-Smirnov test to examine distribution goodness of all studied variables and, according to this test, all variables were found to fit normal distribution. Means and standard deviation $(\mathrm{m} \pm \mathrm{SD})$ were calculated for all anthropometric parameters and associated factors. Comparison of independent samples was performed using Student's $\mathrm{t}$-test and a value of $\mathrm{p}<0.05$ was considered statisti- 
cally significant. With the use of the chi square test we evaluated differences in categorical variables. SPSS (v.15) was used for the statistical analysis.

\section{RESULTS}

All the anthropometric characteristics of the sample in total and separately according to ethnicity are shown in Table $1.26 .1 \%$ of the boys and $22.4 \%$ of the girls were overweight and a further $11.6 \%$ of boys and $10.9 \%$ of girls were obese. Overweight and obesity rates were significantly lower in immigrant children (10\% and $3.3 \%$, respectively) compared to Greek children $(25.8 \%$ and $12.7 \%$, respectively), $\mathrm{p}=0.024$ for both. No difference was found in the prevalence of obesity between children from urban and rural areas.

When associated factors were evaluated, we found that a) parental obesity was positively related to childhood obesity $(\mathrm{p}=0.001)$, b) obese children compared to their non-obese counterparts were receiving less pocket money $(\mathrm{p}=0.004)$ and $\mathrm{c})$ a higher percentage of obese children reported that food preparation
Table 1. Anthropometric characteristics according to ethnicity

\begin{tabular}{lccc}
\hline & & \multicolumn{2}{c}{ ETHNICITY } \\
\cline { 3 - 4 } & $\begin{array}{c}\text { TOTAL } \\
(\mathbf{n = 2 6 6})\end{array}$ & $\begin{array}{c}\text { Greeks } \\
(\mathbf{n = 2 3 6})\end{array}$ & $\begin{array}{c}\text { Immigrants } \\
(\mathbf{n = 3 0})\end{array}$ \\
\hline Age (yrs) & $9.98 \pm 0.95$ & $9.92 \pm 0.92$ & $10.40 \pm 1.07$ \\
Weight (Kg) & $39.01 \pm 9.83$ & $39.01 \pm 9.74$ & $38.23 \pm 8.71$ \\
Height (cm) & $1.42 \pm 0.08$ & $1.41 \pm 0.08^{*}$ & $1.45 \pm 0.09$ \\
Body Mass Index & $19.26 \pm 3.54$ & $19.39 \pm 3.55^{*}$ & $17.97 \pm 2.38$ \\
$\quad($ Kg/m $)$ & & & \\
Waist circumference & $66.48 \pm 9.51$ & $66.69 \pm 9.33$ & $63.86 \pm 8.29$ \\
$\quad(\mathrm{~cm})$ & & & \\
Hip circumference & $80.04 \pm 8.85$ & $80.12 \pm 8.74$ & $78.75 \pm 8.09$ \\
$\quad$ (cm) & & & \\
Waist to Hip Ratio & $0.83 \pm 0.52$ & $0.83 \pm 0.05^{*}$ & $0.80 \pm 0.04$ \\
Body Fat (\%) & $21.88 \pm 8.46$ & $22.33 \pm 8.57^{* *}$ & $17.96 \pm 5.81$ \\
Overweight (\%) & 24.1 & $25.8^{*}$ & 10.0 \\
Obese (\%) & 11.7 & $12.7^{*}$ & 3.3 \\
\hline
\end{tabular}

* Significant difference between groups, $\mathrm{p}<0.05$

** Significant difference between groups, $\mathrm{p}<0.001$

was carried out by their grandmother compared with normal weight children $(\mathrm{p}=0.006)$ (Table 2$)$. Table

Table 2. Prevalence of an obese parent, pocket money in euro/day and food preparer in the family, according to obesity status (in absolute numbers and percentages)

\begin{tabular}{lcccc}
\hline & \multicolumn{2}{c}{ Students } & Total & P value \\
\cline { 2 - 3 } Obese parent & Non-obese & Obese & & \\
$\quad$ Yes & & & $111(100 \%)$ & 0.001 \\
No & $89(80.2 \%)$ & $22(19.8 \%)$ & $161(100 \%)$ & \\
Total & $151(93.8 \%)$ & $10(6.2 \%)$ & $272(100)$ & \\
Pocket money in euros/day & $240(88.2 \%)$ & $32(11.8 \%)$ & & \\
0 & & & $10(100 \%)$ & \\
$<1$ & $6(60.0 \%)$ & $4(40.0 \%)$ & $77(100 \%)$ & \\
$1-5$ & $65(84.4 \%)$ & $12(15.6 \%)$ & $178(100 \%)$ & \\
$>5$ & $163(91.6 \%)$ & $15(8.4 \%)$ & $2(100 \%)$ & \\
Total & $1(50.0 \%)$ & $1(50.0 \%)$ & $267(100 \%)$ & \\
Food preparer & $235(88.0 \%)$ & $32(12.0 \%)$ & & \\
Mother & & & $255(100 \%)$ & \\
Grandmother & $229(98.8 \%)$ & $26(10.2 \%)$ & $15(100 \%)$ & \\
Father & $9(60 \%)$ & $6(40 \%)$ & $2(100 \%)$ & \\
Other & $2(100.0 \%)$ & $0(0 \%)$ & $1(100 \%)$ & \\
Total & $1(100.0 \%)$ & $0(0.0 \%)$ & $273(100 \%)$ & \\
\hline
\end{tabular}


2 also presents absolute and relative frequencies for better appreciation of the effect of each factor (row) on the result (column).

Total energy and carbohydrate daily intakes were significantly higher in immigrants compared to Greeks $(1611 \pm 599 \mathrm{Kcal}$ vs $1363 \pm 471 \mathrm{Kcal}, \mathrm{p}=0.036$ and $188.31 \pm 70.63 \mathrm{~g}$ vs $149.87 \pm 56.41 \mathrm{~g}, \mathrm{p}=0.001$, respectively). Furthermore, consumption of bread and cereals was found significantly higher in immigrants compared to Greeks and this is in accordance with the higher carbohydrate intakes (Table 3). Although

Table 3. Food group equivalents according to ethnicity

\begin{tabular}{lcc}
\hline & \multicolumn{2}{c}{ ETHNICITY } \\
\cline { 2 - 3 } & Greeks & Immigrants \\
\hline Milk Equivalents & $2.34 \pm 1.01$ & $2.51 \pm 1.10$ \\
Fruit Equivalents & $2.21 \pm 2.20$ & $2.35 \pm 2.32$ \\
Vegetable Equivalents & $1.43 \pm 1.43$ & $2.26 \pm 3.30$ \\
Bread \& Cereal Equivalents & $5.44 \pm 2.95^{*}$ & $7.38 \pm 3.90$ \\
Meat Equivalents & $3.66 \pm 3.51$ & $3.30 \pm 2.69$ \\
Fat Equivalents & $11.60 \pm 6.23$ & $8.99 \pm 3.75$ \\
\hline
\end{tabular}

* Significant difference between groups, $\mathrm{p}<0.05$

Table 4. Energy, nutrient intake and physical activity, according to ethnicity

\begin{tabular}{lcc}
\hline & \multicolumn{2}{c}{ ETHNICITY } \\
\cline { 2 - 3 } & Greeks & Immigrants \\
\hline Energy Intake (Kcal) & $1363 \pm 471^{*}$ & $1611 \pm 599$ \\
Carbohydrates $(\%)$ & $43.87 \pm 10.74^{*}$ & $46.53 \pm 8.75$ \\
Carbohydrates $(\mathrm{g})$ & $149.87 \pm 56.41^{* *}$ & $188.31 \pm 70.63$ \\
Carbohydrates $(\mathrm{g} / \mathrm{KgBW})$ & $4.13 \pm 1.98^{*}$ & $5.12 \pm 2.15$ \\
Proteins $(\%)$ & $18.18 \pm 5.68$ & $16.97 \pm 3.67$ \\
Proteins $(\mathrm{g})$ & $62.41 \pm 28.68$ & $69.94 \pm 30.65$ \\
Proteins $(\mathrm{g} / \mathrm{KgBW})$ & $1.70 \pm 0.88$ & $1.90 \pm 0.89$ \\
Fat $(\%)$ & $37.98 \pm 8.67$ & $36.47 \pm 7.91$ \\
Fat $(\mathrm{g})$ & $59.68 \pm 28.19$ & $68.24 \pm 32.80$ \\
Fat $(\mathrm{g} / \mathrm{KgBW})$ & $1.64 \pm 0.91$ & $1.86 \pm 1.00$ \\
Exercise $(\mathrm{h} / \mathrm{w})$ & $4.14 \pm 4.18^{*}$ & $6.38 \pm 7.22$ \\
TV, PC $(\mathrm{h} / \mathrm{d})$ & $1.54 \pm 0.71$ & $1.76 \pm 0.87$ \\
\hline
\end{tabular}

${ }^{*}$ Significant difference between groups, $\mathrm{p}<0.05$

** Significant difference between groups, $\mathrm{p}<0.001$

BW: body weight the total energy expenditure was not measured, it can be seen via the results of the questionnaire that physical activity was higher among immigrants compared to Greeks. The mean BMI value was lower in immigrant children. No difference between the two groups was found as far as television viewing is concerned (Table 4).

\section{DISCUSSION}

According to the results of this study, a large proportion of children living in Thessaloniki have a high prevalence of overweight ( $26.1 \%$ of boys and $22.4 \%$ of girls) and obesity (11.6\% of boys and $10.9 \%$ of girls). In another study previously carried out in Thessaloniki in 6-10yr-old children, the prevalence of overweight and obesity was $25.3 \%$ and $5.6 \%$, respectively, ${ }^{15}$ while a study in 11 - 14yr-old adolescents showed that $31 \%$ of boys and $21 \%$ of girls were overweight ${ }^{16}$.

From our study some interesting factors associated with obesity emerged. The majority $(68.8 \%)$ of the obese children had an obese parent, while the respective percentage for non-obese children was $37.1 \%$, $(\mathrm{p}<0.05)$. Children that come from two obese parents have higher odds of becoming obese, lower when one parent is obese and minimal when no parent suffers from obesity. ${ }^{17}$ In the study by Unger et al., ${ }^{18}$ $63 \%$ of obese children had obese mothers, $14 \%$ had obese fathers and half of the obese children had obese brothers and sisters. An obese parent bequeaths to the children the tendency towards obesity, particularly when the parent was already obese in childhood or adolescence. ${ }^{19}$ This tendency, however, is expressed in an environment that promotes its expression. Stunkard et al. ${ }^{20}$ showed that muscular mass and skeletal size are hereditary and, indeed, there was a high correlation of children's BMI with that of their biological parents but obesity prevalence between the children and their biological or their adoptive parents did not differ significantly. In an earlier similar study in Thessaloniki, the fathers' and mothers' BMI was found to influence positively and independently the children's BMI. ${ }^{21}$

In the present study, a fivefold percentage of obese children compared to non-obese stated that they were eating their grandmother's cooking. Grandparents tend to overindulge their grandchildren, particularly 
by preparing both delicious and fattening dishes. Young mothers in Greece usually complain that they cannot persuade their own mothers not to overfeed their children. It should be mentioned that it is still common-although this is slowly changing-that grandmothers take care of their grandchildren while their parents are working, resulting in grandmothers being responsible for preparing the family's food. It should be highlighted that grandmothers in Greece still possess the so called "war syndrome", in other words the notion that "food should be consumed in abundance whenever it is available". Older age Greeks experienced extreme poverty and famine during the first half of the $20^{\text {th }}$ century because of a long and distressful period of wars in Greece, while a significant percentage of them were also illiterate $(21.5 \%$ and $26.3 \%$ of men and women, respectively). ${ }^{22}$

Our obese children compared to their non-obese counterparts were receiving significantly less pocket money $(\mathrm{p}<0.05)$. The reason for this may be the fear of the parents of the obese children that the pocket money will be spent on unhealthy snacks in school and this will further contribute to obesity. Another possible explanation might be the relationship between low socioeconomic status and obesity. In addition, fast food is usually of low-cost, which makes it an appealing food option, especially for low socioecomic families. ${ }^{6}$

An interesting novel finding in the present study is the fact that the overweight and obesity rate was found to be three times higher in Greeks (25.8\% and $12.7 \%)$ compared to immigrants (10\% and $3.3 \%$, respectively). Immigrant children probably follow a more proper nutrition and lifestyle behaviour that results in lower BMI and percentage of body fat values. This result is not in accordance with other developed countries., ${ }^{9,23}$ In economically developed countries, children belonging to specific racial or ethnic groups are at greater risk for overweight or obesity. ${ }^{24}$ The explanation for this is that immigration is a very new phenomenon in Greece and these immigrant children are often following a more traditional lifestyle and have not yet been affected by a westernized diet, compared to Greek children. Data from other countries showed that adolescent immigrants from Asia and Spain that were born in America had more than double the likelihood of being obese than first generation immigrants. ${ }^{25}$ Immigrant children from Turkey and former Yugoslavia had a higher possibility of being overweight than native Austrian children. ${ }^{23}$ According to a study by Roville-Sausse, ${ }^{9}$ Chinese children who lived in France had lower energy intake than French children.

In fact, Greek children are more obese than immigrant children despite a lower energy intake. A possible explanation for this can be that obese Greek children often underestimate food consumption. Dietary under-reporting in obese subjects has been shown by many studies. . $^{1626-30}$

The significantly higher carbohydrate intake that was observed in immigrants can be attributed to the fact that immigrants consumed more bread and cereal products than Greeks. Furthermore, immigrants reported eating 4.61 servings of fruits and vegetables daily while Greeks only 3.64, the recommended amount being 5 servings per day. ${ }^{31}$ Similar results regarding inadequate consumption of fruits and vegetables have been reported by other investigators. According to a study by Janssen et al., ${ }^{7}$ less than half of adolescents consumed fruits and vegetables more than once per day. It is worth noting that according to U.S. Senator Tom Harkin, ${ }^{32}$ only $2 \%$ of the food industry advertising is for fruits and vegetables, while the overwhelming majority is for "unhealthy" foods high in sugar, fat and salt content. Studies evaluating dietary habits in young Greeks ${ }^{16,33}$ and Spaniards ${ }^{29}$ showed that consumption of carbohydrates and fibers is relatively low, especially among overweight individuals.

Another explanation for a lower rate of obesity in the immigrant children could be the amount of exercise. Thus, in the present study immigrants exercised significantly more than Greeks. This partly explains their lower BMI values. In other words, although immigrants had higher energy intake, they also had higher energy expenditure and the latter possibly leads to a leaner phenotype. This also indicates that they have not yet adopted a westernised sedentary lifestyle. In general, fewer adolescents and adults from southern European countries participate in some kind of physical activity with Greece being the country with the lowest number of participants (61\%) after Portugal. ${ }^{34}$ It should be stressed that the number of 
immigrant children that participated in the present study is relatively low, so that conclusions should be drawn with caution. This is, in fact, a limitation of the present study. Besides environmental factors, the genetic background of the various ethnic groups may also partially explain the differences in the rate of obesity between immigrants and native population.

The high rate of pediatric overweight and obesity, when combined with the aforementioned findings of improper nutrition and physical inactivity, points to the need for the design of improved health campaigns. More effective public heath interventions aiming at improving nutrition and decreasing sedentary activities while increasing physical activity participation are necessary for both prevention and treatment of childhood obesity. ${ }^{7}$ Health education in school should be accompanied by playground opportunities and healthier canteen food. This might include the use of school play areas after school hours as well as active commuting to schools, like walking or bicycling to school. ${ }^{8,35}$

The main advantage of the present regional study lies in the fact that it investigated eating and physical activity behaviors both in Greek and immigrant children. Cultural differences seem important but are unfortunately frequently overlooked when people deal with obesity. A study by Christakis and Fowler ${ }^{36}$ suggests that obesity may spread in social networks depending on the nature of social ties. According to this study, ${ }^{36}$ a person's chances of becoming obese increased by $37 \%$ if one spouse became obese and by $57 \%$ if he or she had a friend who became obese in a given interval. Therefore, there is a need to approach obesity not only as a clinical problem but also as a public health problem. ${ }^{36}$ This approach is also highlighted by the findings of the present study.

In conclusion, before any intervention in childhood obesity is undertaken, specific sociodemographic factors in addition to food intake and physical activity need to be considered. Knowledge of the traditional food practices among the different immigrant communities is a crucial health issue in order to take steps towards counseling immigrant families. Additionally, we could suggest that the lifestyle (dietary habits and physical activity) of immigrant children might provide a good model for healthy body weight in young Greeks.
However, more studies on more representative samples are needed to clarify this important issue.

\section{REFERENCES}

1. Hedley AA, Ogden CL, Johnson CL, Carroll MD, Curtin LR, Flegal KM, 2004 Prevalence of overweight and obesity among US children, adolescents, and adults, 1999-2002. JAMA 291: 2847-2850.

2. Booth ML, Chey T, Wake M, et al, 2003 Change in the prevalence of overweight and obesity among young Australians, 1969-1997. Am J Clin Nutr 77: 29-36.

3. Tzotzas T, Krassas GE, 2004 Prevalence and trends of obesity in children and adults of South Europe. Pediatr Endocrinol Rev 1: 448-454.

4. Jackson-Leach R, Lobstein T, 2006 Estimated burden of paediatric obesity and co-morbidities in Europe. Part 1. The increase in the prevalence of child obesity in Europe is itself increasing. Int J Pediatr Obes 1: 26-32.

5. French SA, Story M, Jeffery RW, 2001 Environmental influences on eating and physical activity. Annu Rev Public Health 22: 309-335.

6. Lob-Corzilius T, 2007 Overweight and obesity in childhood - a special challenge for public health. Int $\mathrm{J}$ Hyg Environ Health 210: 585-589.

7. Janssen I, Katzmarzyk PT, William F, Boyce WF, King MA, Picket W, 2004 Overweight and obesity in Canadian adolescents and their associations with dietary habits and physical activity patterns. J Adolesc Health 35: 360367.

8. Ells LJ, Caampbell K, Lidstone J, Kelly S, Lang R, Summerbell C, 2005 Prevention of childhood obesity.Best Pract Res Clin Endocrinol Metab 19: 441-454.

9. Roville-Sausse FN, 2005 Westernization of the nutritional pattern of Chinese children living in France. Public Health 119: 726-733.

10. LaRowe TL, Moeller SM, Adams AK, 2007 Beverage patterns, diet quality, and body mass index of US preschool and school-aged children. J Am Diet Assoc 107: 1124-1133.

11. Slaughter MH, Lohman TG, Boileau RA, et al, 1988 Skinfold equations for estimation of body fatness in children and youth. Hum Biol 60: 709-723.

12. Cole TJ, Belizzi MC, Flegal KM, Dietz WM, 2000 Establishing a standard definition for child overweight and obesity worldwide: International survey. BMJ 320: 1240-1243.

13. Lappalainen R, Kearney J, Gibney M, 1998 A pan EU survey of consumer attitudes to food, nutrition and health: an overview. Food Qual Pref 9: 467-478.

14. Papadopoulou SK, Barboukis V, Dalkiranis A, Hassapidou M, Petridou A, Mougios V, 2008 Validation of a questionnaire assessing food frequency and nutrition intake in Greek adolescents. Int J Food Sci Nutr 59: 148-154. 
15. Krassas GE, Tzotzas T, Tsametis C, Konstantinidis T, 2001 Prevalence and trends in overweight and obesity among children and adolescents in Thessaloniki, Greece. J Pediatr Endocrinol Metab 14: 1319-1326.

16. Hassapidou M, Fotiadou E, Maglara E, Papadopoulou SK, 2006 Energy intake, diet composition, energy expenditure, and body fatness of adolescents in northern Greece. Obesity 14: 855-862.

17. Garn SM, Clark DC, 1976 Trends in fatness and the origins of obesity Ad Hoc Committee to Review the Ten-State Nutrition Survey. Pediatrics 57: 443-456.

18. Unger R, Kreeger L, Christoffel KK, 1990 Childhood obesity. Medical and familial correlates and age of onset. Clin Pediatr (Phila) 29: 368-373.

19. McCarty B, Mellin L 1996 Adolescent Nutrition Assessment and Management. In: Rickert IV (ed) Obesity, Chapman \& Hall, New York; pp, 199-219.

20. Stunkard AJ, Swrensen TI, Hanis C, et al, 1986 An adoption study of human obesity. N Engl J Med 314: 193-198.

21. Krassas GE, Tzotzas T, Tsametis C, Konstantinidis T, 2001 Determinants of body mass index in Greek children and adolescents. J Pediatr Endocrinol Metab 14: 13271333.

22. Papadopoulou SK, Papadopoulou SD, Zerva A, et al, 2003 Health status and socioeconomic factors as determinants of physical activity level in the elderly. Med Sci Monit 9: 79-83.

23. Kirchengast S, Schober E, 2006 Immigration as a risk factor for developing overweight and obesity during childhood and adolescence. J Biosoc Sci 38: 695-705.

24. Wang Y, Lobstein T, 2006 Worldwide trends in childhood overweight and obesity. Int J Pediatr Obes 1: 11-25.

25. Popkin BM, Udry JR, 1998 Adolescent obesity increases significantly in second and third generation U.S. immigrants: the National Longitudinal Study of Adolescent Health. J Nutr 128: 701-706.
26. Miller WC, Lindeman AK, Wallace J, Niederpreum M, 1990 Diet composition, energy intake, and exercise in relation to body fat in men and women. Am J Clin Nutr 52: 426-430.

27. Johansson L, Solvoli K, Gunn-Elin AB, Drevon CA, 1998 Under- and overreporting of energy intake related to weight status and lifestyle in a nationwide sample. Am J Clin Nutr 68: 266-274.

28. Macdiarmid JI, Blundell JE, 1997 Dietary under-reporting: what people say about recording their food intake. Eur J Clin Nutr 51: 199-200.

29. Ortega RM, Requejo AM, Andres P, Lopez-Sobaler AM, Redondo R, Gonzales-Fernandez M, 1995 Relationship between diet composition and body mass index in a group of Spanish adolescents. Br J Nutr 74: 765-773.

30. Bandini LG, Schoeller DA, Cyr HN, Dietz WH, 1990 Validity of reported energy intake in obese and non-obese adolescents. Am J Clin Nutr 52: 421-425.

31. ADA Reports, 2005 Position of the American Dietetic Association: Benchmarks for Nutrition Programs in child care settings. J Am Diet Assoc 105: 979-986.

32. Harkin T, 2007 Preventing childhood obesity: the power of policy and political will. Am J Prev Med 33: S165-166.

33. Roma-Giannikou E, Adamis D, Gianniou M, Nikolara R, Matsaniotis N, 1997 Nutritional survey in Greek children: nutrient intake. Eur J Clin Nutr 51: 273-285.

34. Vaz de Almeida MD, Grana P, Afonso C, D'Amicis A, Lappalainen R, Damkjaer S, 1999. Physical activity levels and body weight in a nationally representative sample in the European Union. Public Health Nutr 2: 105-113.

35. Staunton CE, Hubsmith D, Kallins W, 2003 Promoting safe walking and biking to school: the Marin County success story. Am J Public Health 93: 1431-1434.

36. Christakis NA, Fowler JH, 2007. The Spread of Obesity in a Large Social Network over 32 Years. N Engl J Med 357: $370-379$. 